ARTICLE

https://doi.org/10.1038/s41467-019-13348-2

\title{
Structural basis of ligand selectivity and disease mutations in cysteinyl leukotriene receptors
}

\author{
Anastasiia Gusach (10) 1,14, Aleksandra Luginina1,14, Egor Marin¹, Rebecca L. Brouillette2 , Élie Besserer-Offroy (1) 2, \\ Jean-Michel Longpré ${ }^{2}$, Andrii Ishchenko (10 3,4,11, Petr Popov ${ }^{1,12}$, Nilkanth Patel ${ }^{3,5}$, Taku Fujimoto6, \\ Toru Maruyama6, Benjamin Stauch (10 3,4, Margarita Ergasheva1', Daria Romanovskaia (1) 1,13, \\ Anastasiia Stepko (10) 1, Kirill Kovalev1,7,8,9,10, Mikhail Shevtsov1, Valentin Gordeliy 1,7,8,9,10, Gye Won Han ${ }^{3,4}$, \\ Vsevolod Katritch (10 3,4,5, Valentin Borshchevskiy (1) ${ }^{1,7,9}$, Philippe Sarret ${ }^{2 \star}$, Alexey Mishin (1) ${ }^{1 \star}$ \& \\ Vadim Cherezov (iD) $1,3,4,5 *$
}

Cysteinyl leukotriene $G$ protein-coupled receptors $\mathrm{CysLT}_{1}$ and $\mathrm{Cys}_{2} \mathrm{LT}_{2}$ regulate proinflammatory responses associated with allergic disorders. While selective inhibition of Cys $\mathrm{L}_{1} \mathrm{R}$ has been used for treating asthma and associated diseases for over two decades, Cys $\mathrm{L}_{2} R$ has recently started to emerge as a potential drug target against atopic asthma, brain injury and central nervous system disorders, as well as several types of cancer. Here, we describe four crystal structures of Cys $T_{2} R$ in complex with three dual Cys $L T_{1} R / C y s L T_{2} R$ antagonists. The reported structures together with the results of comprehensive mutagenesis and computer modeling studies shed light on molecular determinants of CysLTR ligand selectivity and specific effects of disease-related single nucleotide variants.

\footnotetext{
${ }^{1}$ Research Center for Molecular Mechanisms of Aging and Age-Related Diseases, Moscow Institute of Physics and Technology, Dolgoprudny, Russia 141701. ${ }^{2}$ Department of Pharmacology-Physiology, Faculty of Medicine and Health Sciences, Institut de Pharmacologie de Sherbrooke, Université de Sherbrooke, Sherbrooke, QC J1H 5N4, Canada. ${ }^{3}$ Bridge Institute, Michelson Center for Convergent Bioscience, University of Southern California, Los Angeles, CA 90089, USA. ${ }^{4}$ Department of Chemistry, University of Southern California, Los Angeles, CA 90089, USA. ${ }^{5}$ Department of Biological Sciences, University of Southern California, Los Angeles, CA 90089, USA. ${ }^{6}$ Ono Pharmaceutical Co., Ltd., 3-1-1 Sakurai, Shimamoto, Mishima, Osaka 618-8585, Japan. ${ }^{7}$ Institute of Complex Systems (ICS), ICS-6: Structural Biochemistry, Research Center Jülich, Jülich, Germany. ${ }^{8}$ Institut de Biologie Structurale Jean-Pierre Ebel, Université Grenoble Alpes-Commissariat à I'Energie Atomique et aux Energies Alternatives-CNRS, Grenoble, France. ${ }^{9}$ JuStruct: Jülich Center for Structural Biology, Research Center Jülich, Jülich, Germany. ${ }^{10}$ Institute of Crystallography, RWTH Aachen University, Aachen, Germany. ${ }^{11}$ Present address: Merck Research Laboratories, Merck \& Co Inc., 770 Sumneytown Pike, West Point, PA 19486, USA. ${ }^{12}$ Present address: Center for Computational and Data Intensive Science and Engineering, Skolkovo Institute of Science and Technology, Bolshoy Boulevard 30, Building 1, Moscow, Russia 121205. ${ }^{13}$ Present address: CeMM Research Center for Molecular Medicine of the Austrian Academy of Sciences, 1090 Vienna, Austria. ${ }^{14}$ These authors contributed equally: Anastasiia Gusach, Aleksandra Luginina *email: Philippe.Sarret@USherbrooke.ca; mishinalexej@gmail.com; cherezov@usc.edu
} 
C ysteinyl leukotrienes $\mathrm{LTC}_{4}, \mathrm{LTD}_{4}$, and $\mathrm{LTE}_{4}$ are lipid mediators of inflammation acting via two $G$ proteincoupled receptors (GPCRs), cysteinyl leukotriene receptor type $1\left(\right.$ CysLT $\left._{1} R\right)$ and type $2\left(\text { CysLT }_{2} R\right)^{1}$. While $\mathrm{LTD}_{4}$ is the favored endogenous ligand for $\mathrm{CysLT}_{1} \mathrm{R}^{2}, \mathrm{CysLT}_{2} \mathrm{R}$ responds equally to $\mathrm{LTC}_{4}$ and $\mathrm{LTD}_{4}{ }^{3}$. CysLTRs exhibit bronchoconstrictive and pro-inflammatory effects and, therefore, have been recognized for their role in asthma, allergic rhinitis, cardiovascular diseases, and cancers ${ }^{4-7}$. Several selective CysLT ${ }_{1} \mathrm{R}$ antagonists, such as zafirlukast, pranlukast, and montelukast, have been approved as antiasthmatic drugs, however, a large fraction of patients does not respond to this therapy ${ }^{8}$. The different expression profiles, tissue distribution, and sensitivity to endogenous ligands for CysLTRs, their heterodimerization and cross regulation $^{9-11}$ as well as the prevalence of asthma-associated polymorphisms in $\mathrm{CysLT}_{2} \mathrm{R}^{12,13}$ suggest distinct roles for each receptor subtype in physiology and pathology. Based on an $\mathrm{LTC}_{4}{ }^{-}$ induced animal asthma model, it was proposed that $\mathrm{CysLT}_{2} \mathrm{R}$ selective or dual antagonists may improve treatments of severe asthma cases ${ }^{14}$. Furthermore, selective inhibition of CysLT $_{2} \mathrm{R}$ predominantly expressed in cardiovascular and brain tissues has shown remedial effects in ischemic conditions and acute brain injuries ${ }^{15}$. The development of more efficient therapies against asthma and related diseases is hampered by the lack of specific knowledge about selectivity and functional mechanisms of CysLTRs, which requires high-resolution structural data. Here, we describe four crystal structures of $\mathrm{CysLT}_{2} \mathrm{R}$ in complex with three dual CysLT $_{1} R / C_{2 y s} T_{2} R$ antagonists (cpds 11a-c, Supplementary Fig. 1, Supplementary Methods) and the results of extensive mutagenesis and computer modeling studies. Along with recently reported structures of $\mathrm{CysLT}_{1} \mathrm{R}$ in complex with zafirlukast and pranlukast ${ }^{16}$, we now have a complete structural view of receptors mediating action of cysteinyl leukotrienes in their inhibited, inactive state.

\section{Results}

$\operatorname{CysLT}_{2} \mathbf{R}$ structure determination. To facilitate crystallization, human CysLT $_{2} \mathrm{R}$ was modified by truncating $\mathrm{N}$ - and C-termini, inserting a thermostabilized apocytochrome $\mathrm{b}_{562} \mathrm{RIL}^{17}$ into the intracellular loop 3 (ICL3), and introducing three stabilizing point mutations ${ }^{18}$ : W51 $1^{1.45} \mathrm{~V}, \mathrm{D} 84^{2.50} \mathrm{~N}$, and $\mathrm{F} 137^{3.51} \mathrm{Y}$ (superscript refers to the Ballesteros-Weinstein GPCR residue numbering scheme $\left.\mathrm{e}^{19}\right)$. The engineered receptor was crystallized in lipidic cubic phase (LCP) ${ }^{20}$ in complex with three antagonists: ONO-2570366 (cpd 11a) (2.4 $\AA$ resolution in two different space groups), ONO-2770372 (cpd 11b; $2.7 \AA$ ), and ONO-2080365 (cpd 11c; $2.7 \AA$ ) (Supplementary Figs. $1-4$ and Supplementary Table 1). To validate the structures and probe the role of key residues, involved in ligand binding and receptor function, we conducted cell surface expression and $\mathrm{IP}_{1}$ stimulation and inhibition assays with a set of 24 mutants (Supplementary Figs. 5 and 6 and Table 1).

Overall architecture of CysLT $_{2} \mathbf{R}$. All CysLT ${ }_{2} \mathrm{R}$ structures adopt the canonical seven-transmembrane helical bundle architecture (Fig. 1a) and are structurally similar to $\mathrm{CysLT}_{1} \mathrm{R}$-pranlukast ${ }^{16}$ (Supplementary Table 2). Overall $\mathrm{CysLT}_{2} \mathrm{R}$ conformations are identical to each other (Supplementary Table 2), except for the structure with cpd $11 \mathrm{c}$, which is described below. Our further analysis, therefore, is focused on the highest resolution CysLT $_{2} \mathrm{R}$ 11a structure, unless noted otherwise. Extracellular loop 2 (ECL2) in CysLT $_{2} \mathrm{R}$ is stabilized by the highly conserved disulfide bond ${ }^{21}$ between $\mathrm{C} 111^{3.25}$ and $\mathrm{C} 187^{\mathrm{ECL} 2}$. An additional disulfide bond is formed between $\mathrm{C} 31^{1.25}$ and C2797.27 (Fig. 1c). Notably, both
TM1 and TM7 are about one helical turn shorter than in CysLT $_{1} \mathrm{R}$, resulting in a $\sim 5 \AA$ shift of ECL3 tip (Fig. 1b).

As expected, CysLT $\mathrm{T}_{2} \mathrm{R}$ structures with antagonists $11 \mathrm{a}$ and $11 \mathrm{~b}$ are captured in a fully inactive state. Similar to inactive structures of $\mathrm{CysLT}_{1} \mathrm{R}$ and other receptors from the $\delta$-branch of class $\mathrm{A}$ GPCRs, the $\mathrm{P}^{5.50}-\mathrm{I}^{3.40}-\mathrm{F}^{6.44}$ microswitch is found in a distinct conformation (Fig. 1e $)^{16}$, previously associated with activation of receptors from other class A GPCR branches. The role of this microswitch in receptors from the $\delta$-branch is apparently different and is likely linked to the substitution of the "toggle switch" $\mathrm{W}^{6.48}$ with $\mathrm{F}^{6.48}$, which prevents this microswitch from accessing its inactive conformation. The highly conserved $\mathrm{D}[\mathrm{E}]$ $\mathrm{R}^{3.50} \mathrm{Y}$ motif, in which $\mathrm{R}^{3.50}$ is stabilized in an inactive conformation via a salt bridge with $\mathrm{D}[\mathrm{E}]^{3.49}$, is replaced by $\mathrm{VR}^{3.50} \mathrm{~F}$ in $\mathrm{CysLT}_{2} \mathrm{R}$ (Fig. 1f). As expected, restoring the canonical ionic lock by $\mathrm{V} 135^{3.49} \mathrm{D}$ in $\mathrm{CysLT}_{2} \mathrm{R}$ decreases the potency of $\mathrm{LTD}_{4}$ while increasing the potency of antagonists through stabilization of the inactive conformation (Table 1). Restoration of $\mathrm{Y}$ in the $\mathrm{D}[\mathrm{E}] \mathrm{RY}$ motif via $\mathrm{F} 137^{3.51} \mathrm{Y}$ mutation, which is also present in the crystallized construct, has no effect on the potency of $\mathrm{LTD}_{4}$ or antagonists. Similarly, the stabilizing mutation $\mathrm{W} 51^{1.45} \mathrm{~V}$ in the crystallized construct has little effect on ligand binding and receptor signaling. Finally, the third crystallization construct mutation D $84^{2.50} \mathrm{~N}$, a known stabilizing mutation in the conserved in class A GPCRs sodium-binding pocket ${ }^{22-24}$, abolishes $\mathrm{LTD}_{4}$-stimulated $\mathrm{IP}_{1}$ production in CysLT $2 \mathrm{R}$, similar to its effect in other receptors ${ }^{25}$. Likewise, $\mathrm{N} 297^{7.45} \mathrm{C}$ in the sodium-binding pocket results in a complete loss of signaling activity. Mutating $\mathrm{N} 301^{7.49} \mathrm{D}$ in the conserved $\mathrm{NP}^{7.50} \mathrm{xxY}$ motif (Fig. 1d) (NPLLY in CysLT ${ }_{2}$ R; DPLLY in CysLT ${ }_{1} R$ ) stabilizes the sodium-binding pocket and thus reduces $\mathrm{LTD}_{4}$ signaling potency 6-fold, while increasing receptor surface expression and $E_{\max }$ (Table 1).

Interestingly, the CysLT ${ }_{2} \mathrm{R}-11 \mathrm{c}$ structure shows a different orientation of the $\mathrm{Y} 221^{5.58}$ microswitch along with a distinct conformation of the intracellular part of TM6, shifted $\sim 5 \AA$ outward compared with other $\mathrm{CysLT}_{2} \mathrm{R}$ structures (Supplementary Fig. 7a). Both changes are consistent with a partially activelike GPCR state ${ }^{26}$, which, however, lacks key activation-related changes in TM7 and sodium pocket. Molecular dynamics (MD) simulations show that this state is distinct from both active and inactive states and highly dynamic (Supplementary Fig. 7b, c), suggesting that $\mathrm{CysLT}_{2} \mathrm{R}-11 \mathrm{c}$ likely represents an intermediate conformational state, selected and stabilized by the crystal lattice.

Unlike CysLT $_{1} \mathrm{R}$ structures, all $\mathrm{CysLT}_{2} \mathrm{R}$ structures, except for the complex with cpd 11c, possess a well-resolved intracellular amphipathic helix 8 (H8) running parallel to the membrane (Fig. 1b). While the function of $\mathrm{H} 8$ is not fully understood, a mounting evidence points toward its importance in the regulation of $\mathrm{G}$ protein and $\beta$-arrestin binding ${ }^{27,28}$. Notably, the junction between TM7 and $\mathrm{H} 8$ in CysLT ${ }_{1} \mathrm{R}$ contains a rare $\mathrm{GG}^{8.48}$ motif, which likely increases dynamics of $\mathrm{H} 8$. On the other hand, position 8.48 in $\mathrm{CysLT}_{2} \mathrm{R}$ is occupied by E310 ${ }^{8.48}$, which stabilizes the junction and the inactive state by forming salt bridges with R $136^{3.50}$ and $\mathrm{K} 244^{6.32}$ (Fig. 1f). Removing these interactions by $\mathrm{E} 310^{8.48} \mathrm{~A}$ or $\mathrm{E} 310^{8.48} \mathrm{G}$ results in a slightly increased potency of $\mathrm{LTD}_{4}$ in $\mathrm{IP}_{1}$ signaling assays (Table 1).

Ligand-binding pocket and ligand-receptor interactions. In all CysLT $_{2} \mathrm{R}$ structures, a strong electron density for the ligand (Supplementary Fig. 4) is present inside the central cavity of the receptor that consists of residues from all seven TMs and ECL2. It has a narrow opening ( $\sim 3 \AA$ diameter) between ECLs into the extracellular space and a larger access cleft ( $\sim \AA$ across) from the lipid bilayer between TM4 and TM5 (Fig. 2a). All antagonists 
Table 1 Signaling and cell surface expression data for CysLT $_{2} R$.

\begin{tabular}{|c|c|c|c|c|c|c|}
\hline Mutation & Mutation location & $\begin{array}{l}\text { LTD }_{4} \\
\mathrm{EC}_{50} \pm \text { s.d. nM }\end{array}$ & $\begin{array}{l}\text { LTD }_{4} \\
E_{\max } \pm \text { s.d. } \\
\% \text { of WT }\end{array}$ & $\begin{array}{l}\text { Cpd 11a } \\
I_{50} \pm \text { s.d. nM }\end{array}$ & $\begin{array}{l}\text { Cpd 11c } \\
\text { IC } C_{50} \pm \text { s.d. nM }\end{array}$ & $\begin{array}{l}\text { Cell surface } \\
\text { expression \% of } \\
\text { WT } \pm \text { s.d. }\end{array}$ \\
\hline Wild type & & $4.4 \pm 0.8[4]$ & $100 \pm 7[4]$ & $14 \pm 6[5]$ & $70 \pm 20[4]$ & $100 \pm 50[5]$ \\
\hline K371.31R & Ligand-binding pocket & $40 \pm 20[2]$ & $110 \pm 20[2]$ & $80 \pm 30[2]$ & $280 \pm 100[2]$ & $43 \pm 8[2]$ \\
\hline W51.45V & CC & $6 \pm 5[2]$ & $180 \pm 60[2]$ & $47 \pm 10[2]$ & $160 \pm 30[2]$ & $540 \pm 100[2]$ \\
\hline $\mathrm{D} 84^{2.50 \mathrm{~N}}$ & CC, sodium pocket & $N / R[2]$ & $\mathrm{N} / \mathrm{R}[2]$ & ND & ND & $480 \pm 190[2]$ \\
\hline Y1193.33F & Ligand-binding pocket & $70 \pm 30[2]$ & $90 \pm 30[2]$ & $100 \pm 40[2]$ & $260 \pm 100[2]$ & $71 \pm 10[2]$ \\
\hline $1126^{3.40} \mathrm{~V}$ & PIF motif & $6 \pm 4[2]$ & $130 \pm 70[2]$ & $20 \pm 10[2]$ & $14 \pm 5[3]$ & $63 \pm 8[2]$ \\
\hline $\mathrm{Y} 127^{3.41} \mathrm{~W}$ & Ligand-binding pocket & $1.2 \pm 0.4[2]$ & $110 \pm 30[2]$ & $500 \pm 400[2]$ & $44 \pm 10[2]$ & $240 \pm 50[2]$ \\
\hline $\mathrm{L} 129^{3.43} \mathrm{Q}$ & Disease related, sodium pocket & $\mathrm{N} / \mathrm{R}[2]$ & $N / R[2]$ & ND & ND & $98 \pm 14[2]$ \\
\hline $\mathrm{V} 135^{3.49} \mathrm{D}$ & DRY motif & $20 \pm 10[2]$ & $50 \pm 20[2]$ & $3 \pm 3[2]$ & $40 \pm 30[2]$ & $35 \pm 15[2]$ \\
\hline F1373.51Y & CC, DRY motif & $8 \pm 2[2]$ & $120 \pm 10[2]$ & $15 \pm 5[2]$ & $70 \pm 20[2]$ & $150 \pm 20[2]$ \\
\hline $\mathrm{S} 169^{4.56} \mathrm{~A}$ & Ligand-binding pocket & $5 \pm 1[2]$ & $120 \pm 30[2]$ & $10 \pm 4[3]$ & $16 \pm 10[3]$ & $130 \pm 50[2]$ \\
\hline $\mathrm{K} 194{ }^{\mathrm{ECL} 2 \mathrm{R}}$ & Ligand-binding pocket & $50 \pm 20[2]$ & $140 \pm 30[2]$ & $60 \pm 30[2]$ & $40 \pm 20[2]$ & $150 \pm 40[2]$ \\
\hline K194 ECL2N & Ligand-binding pocket & $5 \pm 2[2]$ & $110 \pm 20[2]$ & $8 \pm 4[2]$ & $32 \pm 10[2]$ & $47 \pm 13[2]$ \\
\hline L198 ${ }^{5.35} \mathrm{~A}$ & Ligand-binding pocket & $N / R[2]$ & $N / R[2]$ & ND & ND & $150 \pm 30[2]$ \\
\hline$M 2015.38 \mathrm{~A}$ & Ligand-binding pocket & $\mathrm{N} / \mathrm{R}[2]$ & $\mathrm{N} / \mathrm{R}[2]$ & ND & ND & $150 \pm 80[2]$ \\
\hline M2015.38L & Ligand-binding pocket & $\mathrm{N} / \mathrm{R}[2]$ & $N / R[2]$ & ND & ND & $90 \pm 30[2]$ \\
\hline$M 2015.38 V$ & $\begin{array}{l}\text { Disease related, ligand- } \\
\text { binding pocket }\end{array}$ & $100 \pm 50[2]$ & $70 \pm 10[2]$ & $30 \pm 10[3]$ & $60 \pm 20[3]$ & $80 \pm 40[2]$ \\
\hline $\mathrm{N} 2 \mathrm{O}^{5.39} \mathrm{H}$ & Ligand-binding pocket & $>1000[2]$ & $50 \pm 20[2]$ & $290 \pm 100[3]$ & $60 \pm 30[3]$ & $110 \pm 20[2]$ \\
\hline $\mathrm{F} 260^{6.48} \mathrm{~W}$ & Toggle switch & $7 \pm 5[2]$ & $50 \pm 30[2]$ & $40 \pm 20[2]$ & $330 \pm 100[2]$ & $38 \pm 7[2]$ \\
\hline $\mathrm{R} 267^{6.55} \mathrm{~K}$ & Ligand-binding pocket & $90 \pm 60[2]$ & $50 \pm 20[2]$ & $22 \pm 9[3]$ & $100 \pm 30[3]$ & $33 \pm 15[2]$ \\
\hline $\mathrm{H} 284^{7.32} \mathrm{Q}$ & Ligand-binding pocket & $21 \pm 6[2]$ & $120 \pm 10[2]$ & $230 \pm 90[2]$ & $270 \pm 200[2]$ & $170 \pm 20[2]$ \\
\hline $\mathrm{N} 297^{7.45} \mathrm{C}$ & Sodium pocket & $N / R[2]$ & $N / R[2]$ & ND & ND & $105 \pm 11[2]$ \\
\hline N3017.49D & Sodium pocket & $25 \pm 7[2]$ & $120 \pm 40[2]$ & $170 \pm 70[2]$ & $110 \pm 50[2]$ & $180 \pm 40[2]$ \\
\hline$E 310^{8.48} \mathrm{~A}$ & Helix 8 & $1.6 \pm 0.7[2]$ & $60 \pm 20[2]$ & $8 \pm 3[2]$ & $18 \pm 5[2]$ & $10 \pm 9[2]$ \\
\hline $\mathrm{E} 310^{8.48} \mathrm{G}$ & Helix 8 & $0.9 \pm 0.3[2]$ & $90 \pm 20[2]$ & $2 \pm 1[2]$ & $7 \pm 6[2]$ & $26 \pm 4[2]$ \\
\hline 3-Mut & CC & N/R [2] & N/R [2] & ND & ND & $190 \pm 120[2]$ \\
\hline 3-Mut- $\Delta C$ & $\mathrm{CC}$ & $\mathrm{N} / \mathrm{R}[2]$ & N/R [2] & ND & ND & $110 \pm 30[2]$ \\
\hline $\mathrm{CC}$ & $\mathrm{CC}$ & N/R [2] & N/R [2] & ND & ND & $\geq 1,000[2]$ \\
\hline
\end{tabular}

Data are shown for $\mathrm{LTD}_{4}$-induced $\mathrm{IP}_{1}$ accumulation (agonist potency, $E C_{50}$, and efficacy, $E_{\max }$ ) and for inhibition of $L T D_{4}$-induced $\mathrm{IP}_{1}$ production by antagonists (IC $\mathrm{C}_{50}$ values). Cell surface expression is determined by ELISA using anti-HA tag antibody, normalized to the expression of WT CysLT ${ }_{2} R$. All data are shown as mean $\pm s$.d. (number of independent experiments performed in quadruplicates in brackets). All nonresponsive to $\mathrm{LTD}_{4}$ stimulation mutants (N/R) are expressed at the cell surface. ND-not determined, because these mutants did not respond to LTD stimulation. "3-Mut"-three brackets). All nonresponsive to $\mathrm{LD}_{4}$ stimulation mutants (N/R) are expressed at the cell surface. ND-not determined, because these mutants did not respond to $\mathrm{LTD}_{4}$ stimulation. "3-Mut" - three
mutations W51.45 $\mathrm{V}, \mathrm{D} 84^{2.50} \mathrm{~N}$, and F1373.51Y used in the crystallized construct (CC). "3-Mut- $\Delta \mathrm{C}^{\text {" }}$-three mutations W51.45V, D842.50 N, and F1373.51Y and $\Delta 323-346 \mathrm{C}$-terminal truncation, as in CC

a

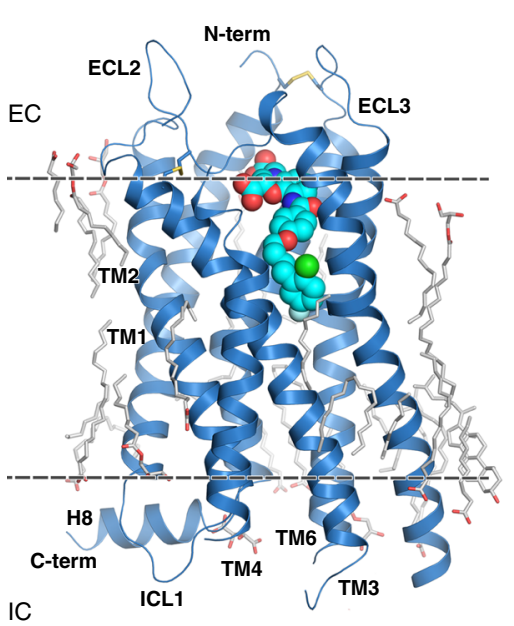

C $\quad$ b



Fig. 1 Structure of CysLT $\mathbf{T}_{\mathbf{2}} \mathbf{R}$. a Overall structure of $C y s L T_{2} R-11$ a ( $C 222_{1}$ space group). b Structural superposition of $C y s L T_{2} R-11 a$ (blue; $C 222_{1}$ space group) with CysLT $R$-pranlukast (yellow). c Comparison of disulfide bridges between $\mathrm{Cys}_{1} \mathrm{~T}_{1} R$ (yellow) and $\mathrm{Cys}_{2} \mathrm{~L} \mathrm{~T}_{2} \mathrm{R}$ (blue). Comparison of functional motifs: $\operatorname{NPxxY}(\mathbf{d}) \mathrm{P}-\mathrm{I}-\mathrm{F}(\mathbf{e})$, and DRY (f). Membrane boundaries are shown as dashed lines in $\mathbf{a}$ and $\mathbf{b}$. 

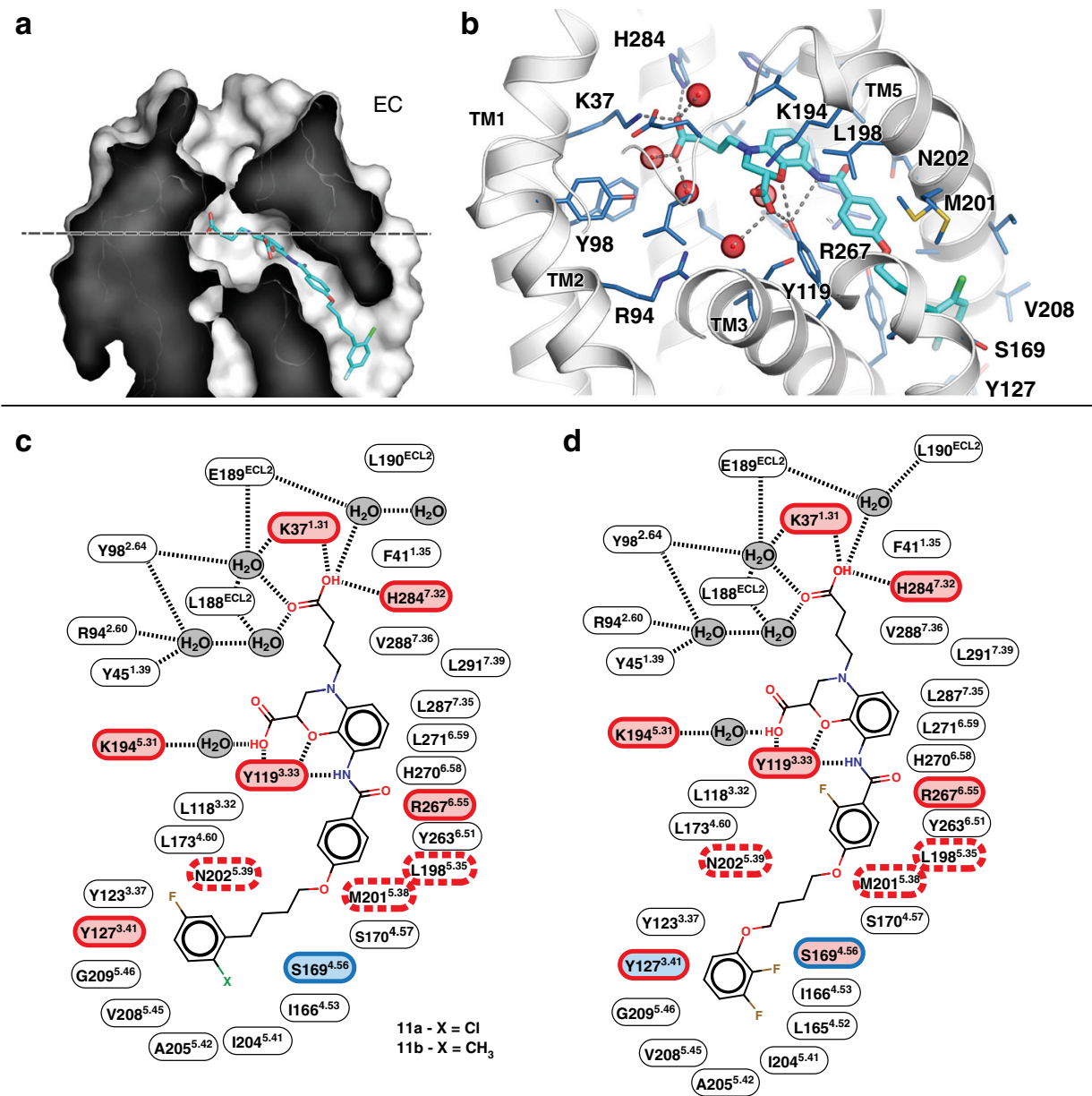

Fig. 2 Ligand-binding pocket of CysLT $\mathbf{T}_{\mathbf{2}} \mathbf{R}$. a Sliced surface representation of the ligand-binding pocket in CysL $T_{2} R$. $\mathbf{b}$ Binding pose of $c p d 11 a$ and details of ligand-receptor interactions. Schematic diagrams of $\mathrm{CysLT}_{2} \mathrm{R}$ interactions with cpds $11 \mathrm{a}$ and $11 \mathrm{~b}$ (c) and cpd 11c (d). Residues are colored according to the effect of their mutations on the antagonist potency in $\mathrm{IP}_{1}$ signaling assays: light red-strong effect, blue-no effect, white-not tested. The outline color indicates the effect of mutations on $\mathrm{LTD}_{4}$ potency: red-strong effect, red dashed-nonresponsive mutants, blue-no effect.

cocrystallized with CysLT $_{2} \mathrm{R}$ share the same 3,4-dihydro-2H-1,4benzoxazine scaffold and bind in the pocket in similar conformations (root mean square deviation $<0.3 \AA$ in the common scaffold, Fig. 2). A key anchoring residue Y1193.33, conserved in CysLTRs, forms multiple polar contacts with the benzoxazine part, carboxylic group, and amide linker of all ligands (Fig. 2b-d). Y119.33 F mutant shows decreased potencies for both $\mathrm{LTD}_{4}$ and antagonists in $\mathrm{IP}_{1}$ assay (Table 1 ). The $\mathrm{N}$-linked carboxypropyl moiety makes salt bridges with $\mathrm{K} 37^{1.31}$ and $\mathrm{H} 284^{7.32}$ that are specific to CysLT $_{2} \mathrm{R}$. Mutating these residues to their $\mathrm{CysLT}_{1} \mathrm{R}$ counterparts $\left(\mathrm{K} 37^{1.31} \mathrm{R}\right.$ or $\left.\mathrm{H} 284^{7.32} \mathrm{Q}\right)$ drastically decreases potencies for $\mathrm{LTD}_{4}$ activation as well as inhibition by antagonists, suggesting distinct binding interactions of these ligands with CysLT $_{1} \mathrm{R}$ and CysLT $_{2} \mathrm{R}$.

The hydrophobic bottom part of the ligand-binding cleft containing the butoxybenzene group of cpd 11a is formed by side chains of TM3-TM5 and, in case of cpd 11c, extends to L165.52 and $1166^{4.53}$. Y127 12.41 forms an interhelical hydrogen bond with the carbonyl oxygen of Val2085.45, stabilizing a Pro-induced kink in TM5 (Fig. 2c, d). An aromatic residue in position 3.41 at the intersection of TM3-TM5 was previously described to confer receptor stabilization ${ }^{29}$. Interestingly, mutation $\mathrm{Y}^{2} 27^{3.41} \mathrm{~W}$ slightly improves CysLT $_{2} \mathrm{R}$ surface expression and potencies of $\mathrm{LTD}_{4}$ and cpd 11c, however, dramatically decreases the potency of cpd 11 a to inhibit $\mathrm{LTD}_{4}$-induced $\mathrm{IP}_{1}$ accumulation, likely because of a clash between bulky tryptophan and 2-chloro-5fluoro-phenyl group of cpd 11a. S169 ${ }^{4.56}$ forms a hydrogen bond with the carbonyl group of $\mathrm{L} 165^{4.52}$ and interacts with the fluorine atom of cpd 11c phenyl group. Mutation $\mathrm{S} 169^{4.56} \mathrm{~A}$ does not affect $\mathrm{EC}_{50}$ for $\mathrm{LTD}_{4}$ and $\mathrm{IC}_{50}$ for cpd 11a but moderately improves inhibition by cpd 11c.

Antagonist selectivity to CysLTR subtypes. To understand the mechanism of ligand selectivity, we performed docking of 18 derivatives of the common 3,4-dihydro-2H-1,4-benzoxazine-2carboxylic acid scaffold 30,31 with a large spectrum of $\mathrm{CysLT}_{1} \mathrm{R} /$ CysLT $_{2} \mathrm{R}$ selectivity (Supplementary Table 3 ). Docking models of the most selective compounds in this structure-activity relationship (SAR) series ${ }^{30}$, cpd 13e (1,800-fold selective for CysLT $\left.{ }_{1} \mathrm{R}\right)$ and cpd 15b (200-fold selective for CysLT ${ }_{2} R$ ), are shown in Fig. 3, alongside with cpd 11a (dual CysLT ${ }_{1} \mathrm{R} / \mathrm{CysLT}_{2} \mathrm{R}$ ), cocrystallized with CysLT $_{2} \mathrm{R}$, and pranlukast (4,500-fold selective for CysLT $\mathrm{T}_{1} \mathrm{R}$ as shown in Supplementary Fig. 6a), cocrystallized with CysLT ${ }_{1} R$.

SAR analysis revealed that the most important factor for CysLT $_{2} \mathrm{R}$ selectivity is the length of the alkyl chain for the Osubstituents $\left(R^{1}\right)$, where longer phenylpentyl group in cpd $15 \mathrm{~b}$ achieves much higher $\operatorname{CysLT}_{2} \mathrm{R}$ selectivity than phenylbutyl in cpd 11a, cpd 13e, and pranlukast or phenylpropyl in some other compounds such as cpd 15a (Supplementary Table 3). Comparison of the contacts of these substituents in CysLT $\mathrm{C}_{1} \mathrm{R}$-pranlukast and CysLT $_{2} \mathrm{R}-11 \mathrm{a}$ suggests that in $\mathrm{CysLT}_{1} \mathrm{R}$ the cleft opening to the lipid membrane is restricted by a hydrophobic ridge formed by $\mathrm{F} 150^{4.52}$, F112 3.41 , and $\mathrm{V} 196^{5.45}$, while in $\mathrm{CysLT}_{2} \mathrm{R}$ the 
a

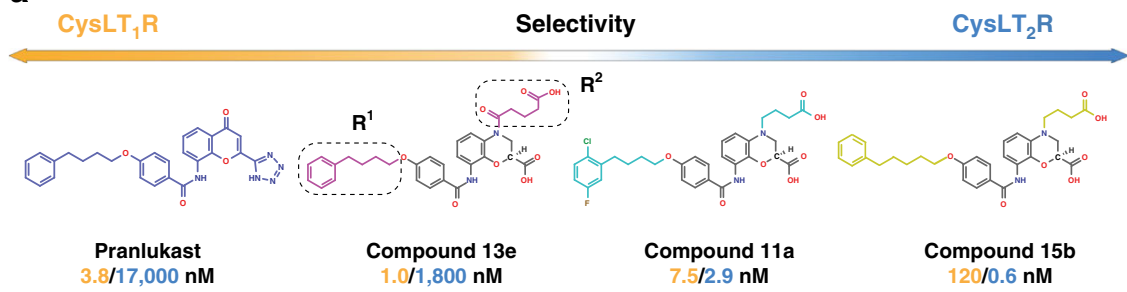

b
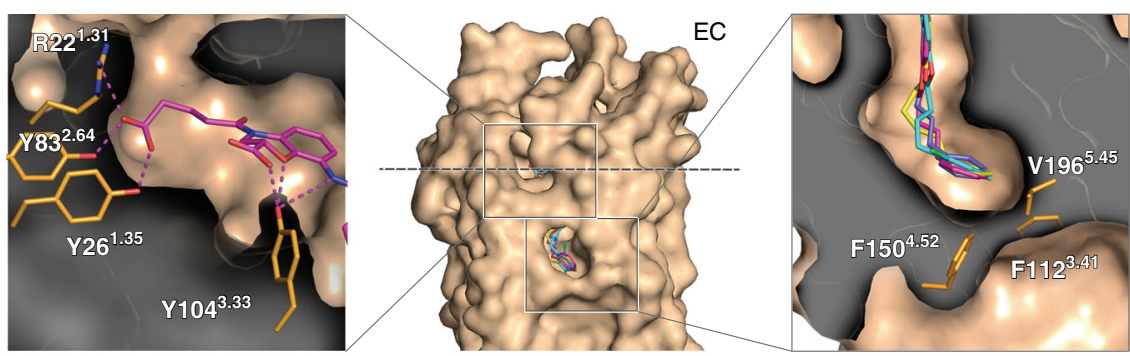

C
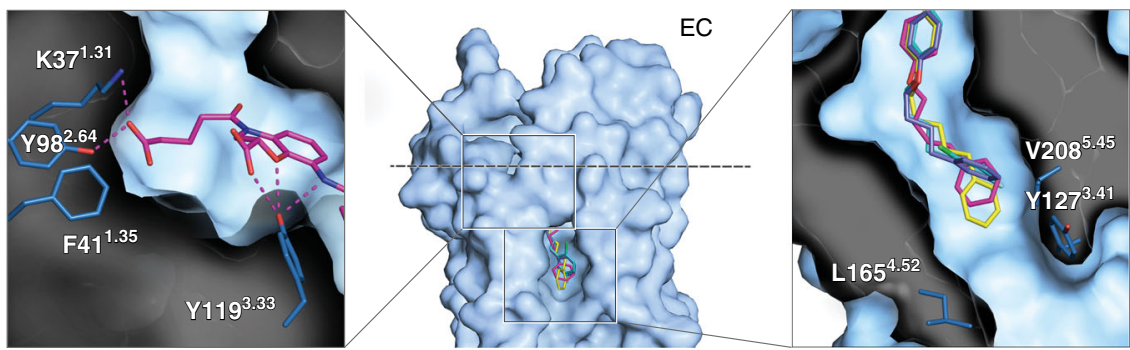

Fig. 3 Structural determinants of antagonist selectivity to CysLTR subtypes. a Examples of compounds used in the docking studies, with their $I_{50}$ values toward CysLT $R$ and CysL $T_{2} R$ shown in yellow and blue, respectively. $I C_{50}$ values for pranlukast were obtained in this work (3.8 $\pm 0.7 \mathrm{nM}\left(\mathrm{Cys} L T_{1} R\right)$ and $\sim 17,000 \pm 12,000 \mathrm{nM}(\mathrm{CysLT} R$ ), expressed as mean \pm s.d. of three independent experiments, tested in quadruplicate) and for other ligands were quoted from ref. ${ }^{30}$. The common 3,4-dihydro-2H-1,4-benzoxazine-2-carboxylic acid scaffold is shown in gray. Overview of the ligand-binding pocket with the docked ligands for $\mathrm{CysLT}_{1} R(\mathbf{b})$ and $\mathrm{Cys}_{2} \mathrm{~T}_{2} R(\mathbf{c})$. Inserts show docking poses and details of ligand interactions with $\mathrm{Cys}_{\mathrm{s}} L T_{1} R$ and $\mathrm{Cys}_{\mathrm{s}} L T_{2} R$.

replacement $\mathrm{F}^{4.52} \mathrm{~L}$ removes this restriction, making the cleft more open. Accordingly, docking of cpd $15 \mathrm{~b}$ into CysLT $\mathrm{R}_{1} \mathrm{R}$ results in a strained alkyl chain and a clash of the terminal phenyl group with $\mathrm{F} 150^{4.52}$, while in $\mathrm{CysLT}_{2} \mathrm{R}$ the phenyl group readily extends outside of the cleft (Fig. 3b, c). Moreover, the phenylbutyl group in this and other scaffolds tolerates methyl and halogen decorations in the ortho and meta positions, which enables tuning pharmacological properties of the ligand such as solubility and stability, as exemplified by the development of gemilukast ${ }^{32}$.

SAR analysis of the $\mathrm{N}$-substituent $\left(\mathrm{R}^{2}\right)$ suggests that its length as well as the presence of a carboxyl group in this scaffold has critical influence on $\mathrm{IC}_{50}$ values for both CysLTRs. Indeed, docking of cpd 13e, the most selective antagonist in this series, shows that the oxo-pentanoic-acid moiety of this ligand forms a hydrogen bond with $\mathrm{Y}_{2} 6^{1.35}$, while $\mathrm{CysLT}_{2} \mathrm{R}$ has $\mathrm{F} 41^{1.35}$ at this position and cannot form a hydrogen bond with the ligand (Fig. 3b, c). Further elongation of this derivative chain is limited by the size of this subpocket. Interestingly, removal of the carbonyl group, as in cpds $14 \mathrm{a}-\mathrm{c}$ and $15 \mathrm{~b}$, shifts selectivity toward $\operatorname{CysLT}_{2} \mathrm{R}$, suggesting that a flexible carboxy-alkyl chain is favored for this receptor ${ }^{30}$. Altogether, CysLT $\mathrm{T}_{1} \mathrm{R}$ and $\mathrm{CysLT}_{2} \mathrm{R}$ crystal structures provide atomic level insights into the mechanisms of ligand recognition and subtype selectivity. This knowledge should contribute to the rational design of more efficient antagonists with improved affinity/efficacy or subtype selectivity profiles.

Structural insights into $\mathrm{CysLT}_{2} \mathrm{R}$ disease-related mutations. Finally, our structures provide rational explanations of the two most common disease-associated single-nucleotide variants (SNVs) in $\mathrm{CysLT}_{2} \mathrm{R}: \mathrm{M} 201^{5.38} \mathrm{~V}$, related to atopic asthma ${ }^{13,33}$, and the oncogenic $\mathrm{L} 129^{3.43} \mathrm{Q}$ mutation ${ }^{34,35}$. M201 ${ }^{5.38}$ together with $\mathrm{M} 172^{4.59}, \mathrm{~L}_{173}{ }^{4.60}$, and $\mathrm{L} 198^{5.35}$ define the shape of the hydrophobic part of the ligand-binding pocket. Substitutions of L198 $8^{5.35}$ with alanine or M201 $1^{5.38}$ with alanine or leucine result in nonresponsive mutants that bind $\mathrm{LTD}_{4}$ but fail to stimulate $\mathrm{IP}_{1}$ production. In contrast to the alanine or leucine substitution, the atopic asthma-associated variant $\mathrm{M} 201^{5.38} \mathrm{~V}$ still responds to $\mathrm{LTD}_{4}$ stimulation. However, this mutation significantly decreases $\mathrm{LTD}_{4}$ potency and efficacy to induce $\mathrm{IP}_{1}$ accumulation when compared with the wild-type CysLT $\mathrm{T}_{2} \mathrm{R}$ (Table 1). These results along with a similar effect of $\mathrm{N} 202^{5.39} \mathrm{H}$ suggest the importance of ligand-dependent TM5 displacement in $\mathrm{CysLT}_{2} \mathrm{R}$ activation. Indeed, all three TM5 residues (L198 $5.35, \mathrm{M} 201^{5.38}$, and N202 ${ }^{5.39}$ ) that are important for potency interact with the benzamide core of antagonists, which distinguish them from agonists, and thus likely modulate TM5 conformation and dynamics that control activation (Fig. 4a).

The second disease-relevant SNV, $\mathrm{L} 129^{3.43} \mathrm{Q}$, has been associated with uveal melanoma and blue nevi ${ }^{34-36}$. A hydrophobic amino acid is present in this position in $97 \%$ of class A receptors, most frequently $\mathrm{L}^{3.43}(73 \%)$, but also $\mathrm{M}^{3.43}$ as in CysLT $\mathrm{T}_{1} \mathrm{R}$. Located at the bottom of the sodium pocket, a large hydrophobic side chain in position 3.43 is part of a hydrophobic layer, which is important for stability of the inactive state. Mutation of $\mathrm{L}^{3.43}$ to a polar residue or to a small alanine residue can disrupt the hydrophobic layer (Fig. 4b, c), facilitating water and sodium passage $\mathrm{e}^{37,38}$ and leading 
a

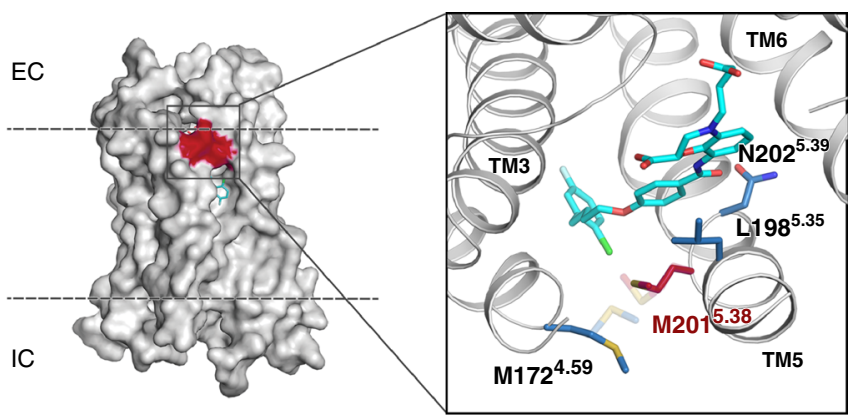

b

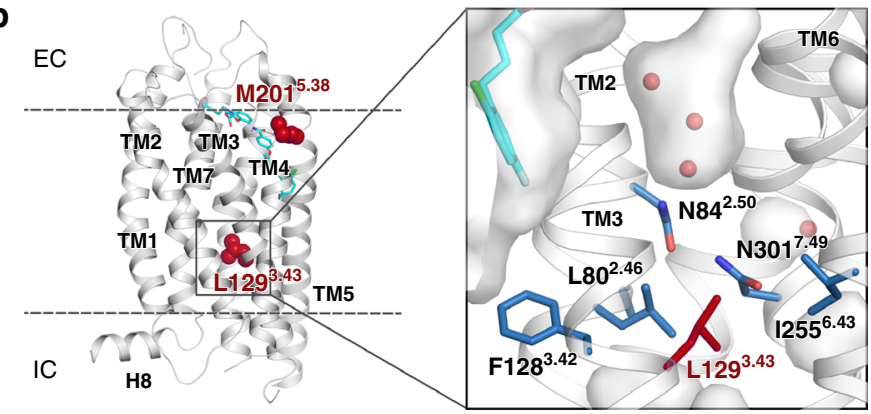

C

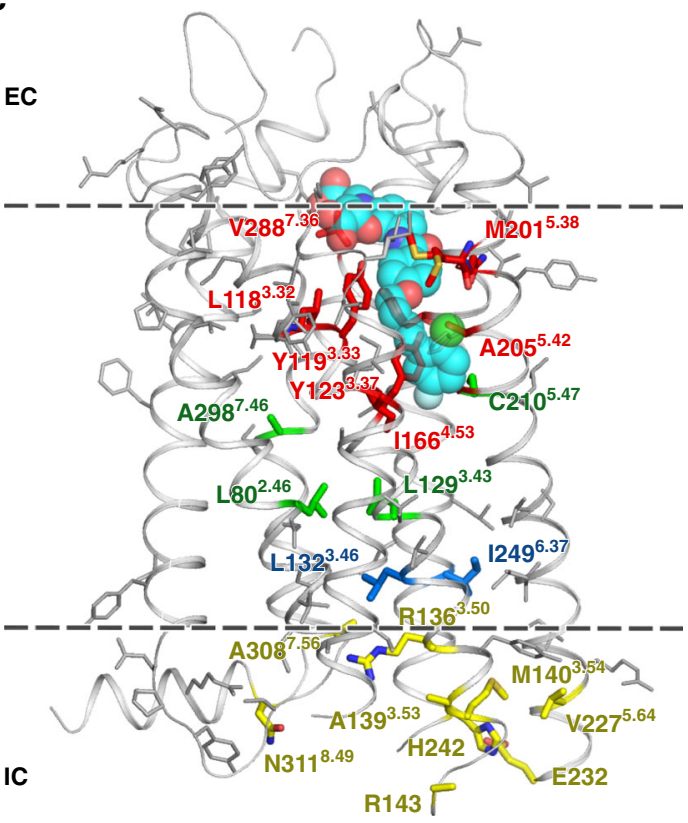

Fig. 4 Naturally occurring missense SNVs, mapped on the $\mathbf{C y s L T}_{\mathbf{2}} \mathbf{R}$ structure. a M2015.38 V polymorphism, associated with atopic asthma. b $\mathrm{L} 129^{3.43} \mathrm{Q}$ mutation, related to uveal melanoma and blue nevi. c SNVs from the ExAC database and L1293.43, colored according to their location: ligand-binding pocket (red), microswitches (blue), sodium site (green), and $\mathrm{G}$ protein and $\beta$-arrestin-binding interface (yellow).

to receptor activation. Indeed, it was shown that mutation in position 3.43 to $\mathrm{R}, \mathrm{K}, \mathrm{A}, \mathrm{E}$, or $\mathrm{Q}$ induces constitutive activation in several receptors ${ }^{39}$, often resulting in distinct physiological disorders. In $\mathrm{CysLT}_{2} \mathrm{R}$, we found that $\mathrm{L} 129^{3.43} \mathrm{Q}$ displays constitutive activity for the $G_{\mathrm{q}}$ pathway with a fourfold increase in basal $\mathrm{IP}_{1}$ accumulation and is unresponsive to $\mathrm{LTD}_{4}$ stimulation (Supplementary Fig. 6b, c).

Further, we evaluated naturally occurring missense SNVs in CysLT $_{2} \mathrm{R}$ from over 60,000 healthy individuals assembled in the exome aggregation consortium (ExAC) database ${ }^{40}$. Structural mapping of $117 \mathrm{SNV}$ positions revealed that nine of them belong to the ligand-binding pocket, seven are activation-related microswitches or located in the sodium-binding site, and nine reside on the $\mathrm{G}$ protein and $\beta$-arrestin-binding interface (Fig. 4c), all of which could dramatically affect the receptor function ${ }^{41}$. Unlike the relatively frequent polymorphisms $\mathrm{M} 201^{5.38} \mathrm{~V}$ or L129 ${ }^{3.43} \mathrm{Q}$, most ExAC mutations are very rare (minor allele frequency $<10^{-4}$ ), and, therefore, it has not been possible yet to associate them with higher risk of asthma or other pathologies.

\section{Discussion}

Compared with CysLT $_{1} \mathrm{R}$, which was successfully targeted by antiasthmatic drugs 20 years ago, the role of $\mathrm{CysLT}_{2} \mathrm{R}$ in physiology and pathogenesis of inflammation related processes is more complex and remains less understood ${ }^{4,42}$. Recently accumulated results suggest that $\mathrm{CysLT}_{2} \mathrm{R}$-selective or $\mathrm{CysLT}_{1} \mathrm{R} /$ CysLT $_{2} \mathrm{R}$ dual antagonists may offer more efficient alternatives to currently used CysLT $\mathrm{T}_{1} \mathrm{R}$-selective antagonists, especially for the treatment of severe asthma ${ }^{43,44}$. In addition, CysLT ${ }_{2} \mathrm{R}$ is arising as a promising drug target against brain injury and neurodegenerative disorders ${ }^{5,45}$. High constitutive $\mathrm{G}_{\mathrm{q}}$ signaling activity of CysLT $_{2} \mathrm{R}$ mutants has been associated with occurrence of uveal melanoma and other cancer types ${ }^{35}$, however, the role of CysLT $_{2} \mathrm{R}$ in cancer remains controversial as its high expression levels have been correlated with antitumorigenic activity ${ }^{46}$.
The CysLT $\mathrm{T}_{2} \mathrm{R}$ structures described in this study along with the structures of $\mathrm{CysLT}_{1} \mathrm{R}^{16}$ reveal important determinants of ligand binding and selectivity between these two receptors. Thus, our docking studies recapitulate binding of dozens of known ligands and allow to explain SAR for a series of 3,4-dihydro-2H-1,4benzoxazine-2-carboxylic acid scaffold derivatives. These structures will serve as templates for rational design of a new generation of potent antagonists with desired selectivity profiles (receptor selective or dual), which could be further developed into efficient drug candidates or tool compounds, helping to decipher the specific role of each of the CysLT receptor subtype in various physiological processes and pathologies.

Our study also provides a key insight into structure and function of the intracellular $\mathrm{H} 8$ in CysLT receptors. While both receptors possess a canonical $\mathrm{H} 8$ amphipathic motif, this helix is well resolved in CysLT $_{2} \mathrm{R}$ structure, but not observed in $\mathrm{CysLT}_{1} \mathrm{R}$ (Fig. 1). The difference is that the junction between TM7 and $\mathrm{H} 8$ in CysLT ${ }_{1} \mathrm{R}$ contains a very flexible GG ${ }^{8.48}$ motif, while CysLT $_{2} R$ has $\mathrm{GE}^{8.48}$ in the same position. Importantly, $\mathrm{G}^{8.48} \mathrm{~S}$ mutation in $\mathrm{CysLT}_{1} \mathrm{R}$ is a known disease mutation that increases efficacy of the receptor signaling $^{16,47}$, likely due to the improved stability of H8, known to be involved in regulation of $\mathrm{G}$ protein and $\beta$-arrestin binding 27,28 . Interestingly, the $\mathrm{E} 310^{8.48}$ side chain in $\mathrm{CysLT}_{2} \mathrm{R}$ serves a special role, forming salt bridges with $\mathrm{R} 136^{3.50}$ and $\mathrm{K} 244^{6.32}$ and thus stabilizing the inactive receptor state. Introduction of Glu in positions 8.48 and 8.49 has been recently shown beneficial effects on stability of the inactive state in several GPCRs, including CB2 $2^{48}$ and $\mathrm{CCR}^{49}$.

Another promising application for structural information obtained in this study is the ability to rationalize effects of specific $\mathrm{SNV}$ s on receptor function. We mapped naturally occurring missense SNVs from 60,000 healthy individuals on the CysLT 2 R structure and observed that about quarter of them are located in functionally important regions, which may affect signaling 40 . Continuing increase in structural coverage of the GPCR superfamily combined with rapid accumulation of genome sequencing data and 
structure-function studies should enable reliable predictions of disease associations and effects of natural missense variants on drug efficacy and safety profiles, advancing us toward the realm of personalized medicine.

\section{Methods}

Protein engineering for structural studies. The wild-type DNA encoding human cysteinyl leukotriene receptor 2 (UniProt Q9NS75) was purchased from cDNA Resource Center (cdna.org) and cloned into a modified pFastBacl vector (Invitrogen) containing an expression cassette with a haemagglutinin signal sequence, FLAG tag, $10 \times$ His tag followed by TEV protease cleavage site on the $\mathrm{N}$-terminus. Amino acids 1-16 from the N-terminus and 323-346 from C-terminus were deleted by overlap extension PCR. Thermostabilized apocytochrome $b_{562}$ RIL (BRIL) from Escherichia coli with mutations M7W, H102I, and R106L was inserted into the ICL3 between the residues E232 and V240 by overlap extension PCR Three point mutations, $\mathrm{W} 51^{1.45} \mathrm{~V}, \mathrm{D} 84^{2.50} \mathrm{~N}$, and $\mathrm{F} 137^{3.51} \mathrm{Y}$, designed using a sequence dissimilarity approach ${ }^{18}$, were further introduced to improve receptor surface expression in Spodoptera frugiperda Sfg cells (Novagen, cat. 71104) as well as its stability and yield. Sequences of all primers used in this work are listed in Supplementary Table 4 . The full DNA sequence of the CysLT ${ }_{2} \mathrm{R}$ crystallization construct is provided in Supplementary Table 5.

Protein expression and purification. Bac-to-Bac baculovirus expression system (Invitrogen) was used to obtain high-titer recombinant baculovirus $\left(>3 \times 10^{8}\right.$ viral particles per ml). Sf9 insect cells were infected at densities $(2-3) \times 10^{6}$ cells per $\mathrm{ml}$ culture at multiplicity of infection of 5-10. BayCysLT2 ligand (Cayman Chemical) was dissolved in DMSO to $25 \mathrm{mM}$ and added to the cell culture at the final concentration of $3 \mu \mathrm{M}$ at the time of infection. Cells were harvested $48-50 \mathrm{~h}$ post infection by gentle centrifugation at $2,000 \times g$ and stored at $-80^{\circ} \mathrm{C}$ until use.

Cells were thawed and lysed by repetitive washes in hypotonic buffer $(10 \mathrm{mM}$ HEPES $\mathrm{pH} 7.5,20 \mathrm{mM} \mathrm{KCl}$, and $10 \mathrm{mM} \mathrm{MgCl}$ ) and high osmotic buffer $(10 \mathrm{mM}$ HEPES pH 7.5, $20 \mathrm{mM} \mathrm{KCl}, 10 \mathrm{mM} \mathrm{MgCl}_{2}$, and $1 \mathrm{M} \mathrm{NaCl}$ ) with addition of protease inhibitor cocktail $(500 \mu \mathrm{M}$ 4-(2-aminoethyl)benzenesulfonyl fluoride hydrochloride (Gold Biotechnology), $1 \mu \mathrm{M}$ E-64 (Cayman Chemical), $1 \mu \mathrm{M}$ leupeptin (Cayman Chemical), $150 \mathrm{nM}$ aprotinin (A.G. Scientific)). Membranes were then resuspended in $10 \mathrm{mM}$ HEPES pH 7.5, $20 \mathrm{mM} \mathrm{KCl}, 10 \mathrm{mM} \mathrm{MgCl}_{2}, 2 \mathrm{mg} \mathrm{ml}^{-1}$ iodoacetamide, protease inhibitors, and $25 \mu \mathrm{M}$ ligand for $30 \mathrm{~min}$ at $4{ }^{\circ} \mathrm{C}$ and then solubilized by addition of $2 \times$ buffer $(300 \mathrm{mM} \mathrm{NaCl}, 2 \%$ of n-dodecyl- $\beta$-D-maltopyranoside (DDM; Avanti Polar Lipids) $0.4 \%$ of cholesteryl hemisuccinate (CHS; Sigma), $10 \%$ glycerol) and incubation for $3.5 \mathrm{~h}$ at $4{ }^{\circ} \mathrm{C}$. All further purification steps were performed at $4{ }^{\circ} \mathrm{C}$. Supernatant was clarified by centrifugation and bound to TALON IMAC resin (Clontech) overnight in presence of $20 \mathrm{mM}$ imidazole and $\mathrm{NaCl}$ added up to $800 \mathrm{mM}$. The resin was then washed with ten column volumes (CV) of wash buffer I $(8 \mathrm{mM}$ ATP, $100 \mathrm{mM}$ HEPES pH 7.5, $10 \mathrm{mM} \mathrm{MgCl}, 500 \mathrm{mM} \mathrm{NaCl}, 15 \mathrm{mM}$ imidazole, $10 \mu \mathrm{M}$ ligand, $10 \%$ glycerol, $0.1 / 0.02 \% \mathrm{DDM} / \mathrm{CHS}$ ), then with five $\mathrm{CV}$ of wash buffer II (25 mM HEPES pH 7.5, $500 \mathrm{mM} \mathrm{NaCl}, 30 \mathrm{mM}$ imidazole, $10 \mu \mathrm{M}$ ligand, $10 \%$ glycerol, $0.015 / 0.003 \% \mathrm{DDM} / \mathrm{CHS})$, then buffer was exchanged into buffer III $(25 \mathrm{mM}$ HEPES $\mathrm{pH}$ 7.5, $500 \mathrm{mM} \mathrm{NaCl}, 10 \mathrm{mM}$ imidazole, $10 \mu \mathrm{M}$ ligand, $10 \%$ glycerol, $0.05 / 0.01 \% \mathrm{DDM} / \mathrm{CHS}$ ) and the protein-containing resin was treated with PNGase F (Sigma) for $5 \mathrm{~h}$. Resin was further washed with five CV of wash buffer III and eluted with $(25 \mathrm{mM}$ HEPES pH 7.5, $250 \mathrm{mM} \mathrm{NaCl}, 400 \mathrm{mM}$ imidazole, $10 \mu \mathrm{M}$ ligand, $10 \%$ glycerol, $0.05 / 0.01 \% \mathrm{DDM} / \mathrm{CHS}$ ) in several fractions. Fractions containing target protein were desalted from imidazole using PD10 desalting column (GE Healthcare) and incubated with $50 \mu \mathrm{M}$ ligand and a His-tagged TEV protease (homemade) overnight to remove the N-terminal tags. Reverse IMAC was performed the following day and protein was concentrated up to $40-60 \mathrm{mg} \mathrm{ml}^{-1}$ using a $100 \mathrm{kDa}$ molecular weight cut-off concentrator (Millipore). The protein purity was checked by SDSPAGE, and the protein yield and monodispersity were estimated by analytical size exclusion chromatography.

LCP crystallization. Purified and concentrated $\mathrm{CysLT}_{2} \mathrm{R}$ was reconstituted in LCP, made of monoolein (Nu-Chek Prep) supplemented with $10 \%(\mathrm{w} / \mathrm{w})$ cholesterol (Affymetrix) in 2:3 protein:lipid ratio using a lipid syringe mixer ${ }^{20}$. Transparent LCP mixture was dispensed onto 96-wells glass sandwich plates (Marienfeld) in $25-40 \mathrm{nl}$ drops and covered with $800 \mathrm{nl}$ precipitant using an NT8-LCP robot (Formulatrix). All LCP manipulations were performed at room temperature (RT, $20-23^{\circ} \mathrm{C}$ ), and plates were incubated and imaged at $22^{\circ} \mathrm{C}$ using an automated incubator/imager (RockImager 1000, Formulatrix). Crystals of CysLT 2 R-11a_C222 grew to their full size within 3 weeks in a precipitant containing $100-200 \mathrm{mM} \mathrm{NH}_{4}$ tartrate dibasic, $28-32 \% \mathrm{v} / \mathrm{v}$ PEG400, and $100 \mathrm{mM}$ HEPES $\mathrm{pH}$ 8.0; CysLT $2 \mathrm{R}-$ 11a_F222 for 3 weeks in a precipitant containing $30 \mathrm{mM} \mathrm{NH}_{4}$ tartrate dibasic, $24 \%$ PEG400, and $100 \mathrm{mM}$ HEPES 7.0; CysLT 2 R-11b for 3 weeks in a precipitant containing $210 \mathrm{mM} \mathrm{NH}_{4}$ tartrate dibasic, 29\% PEG400, and $100 \mathrm{mM}$ HEPES 7.0; and CysLT 2 R-11c for 1 week in a precipitant containing $100 \mathrm{mM} \mathrm{K}$ formate, $30 \% \mathrm{v} / \mathrm{v}$ PEG400, and $100 \mathrm{mM}$ TRIS-HCl pH 8.0. Crystals were harvested from LCP using $75-200 \mu \mathrm{m}$ MiTeGen micromounts and flash-frozen in liquid nitrogen.
Diffraction data collection and structure determination. X-ray diffraction data were collected at the European Synchrotron Radiation Facility (ESRF, Grenoble, France) beamlines ID23-1, ID29, ID30b, and ID30a3, equipped with PILATUS3 6M, PILATUS3 6M-F, or Eiger X 4M detectors, using the X-ray wavelengths in range $0.96770-1.07234 \AA$ and the beam size between 15 and $30 \mu \mathrm{m}$. In case of CysLT ${ }_{2} \mathrm{R}-11 \mathrm{c}$, four partial $\left(70-80^{\circ}\right)$ datasets with oscillation $0.2^{\circ}$ and three partial $20^{\circ}$ datasets with oscillation $0.1^{\circ}$ were collected and combined to obtain a complete final dataset. The exposure was calculated using RADDOSE ${ }^{50}$ based on a dose of 20 MGy per dataset, as implemented in BEST ${ }^{51}$. For CysLT 2 R-11a and CysLT 2 R-11b, partial datasets of $5-15^{\circ}$ per crystal with oscillations of $0.1-0.15^{\circ}$ per image and the exposure time set to reach 20 MGy dose for each partial dataset were collected following a raster scanning of each crystal and selection of best diffraction spots using DOZOR scoring 52 and manual inspection of diffraction images. Data were integrated using XDS, scaled and merged with XSCALE ${ }^{53}$, nonisomorphous datasets were rejected using $\mathrm{CC}_{1 / 2}$-based clustering as previously described ${ }^{52}$. The structure was determined by molecular replacement using phenix.phaser ${ }^{54}$ with the receptor portion of CysLT $_{1}$ R-pran (PDB ID 6RZ4) and BRIL of $\mathrm{A}_{2 \mathrm{~A}} \mathrm{AR}$ (PDB ID 4EIY) as models for the initial cpd 11a structure, and this model was subsequently used as the molecular replacement search model for the three other structures. Initial refinement rounds were performed using autoBUSTER ${ }^{55}$ and at later stages with phenix.refine $e^{56}$, followed with manual examination and rebuilding with $\mathrm{COOT}^{54}$ using both $2 \mathrm{mFo}$ $\mathrm{DFc}$ and $\mathrm{mFo}-\mathrm{DFc}$ maps. Final data collection and refinement statistics are shown in Supplementary Table 1.

Plasmids for functional assays. For $\mathrm{CysLT}_{2} \mathrm{R}$ functional assays, the initial CysLT $_{2} \mathrm{R}$ wild-type gene with an $\mathrm{N}$-terminal $3 \times \mathrm{HA}$ tag cloned into pcDNA3.1+ (Invitrogen) at EcoRI $\left(5^{\prime}\right)$ and $\mathrm{XhoI}\left(3^{\prime}\right)$ was purchased from cDNA.org. All further gene modifications (point mutations, truncations, or partner protein fusion) were introduced by overlapping PCR. Sequences of all primers used in this work are listed in Supplementary Table 4.

$\mathbf{I P}_{\mathbf{1}}$ production assay. The Cisbio IP-One kit was used according to the manufacturer's instructions. HEK293 cells (ATCC CRL-1573) were seeded onto polyL-Lysine-coated 384-well plates at 20,000 cells per well and transfected with $40 \mathrm{ng}$ of DNA coding for the wild-type CysLT ${ }_{2} \mathrm{R}$ or for the CysLT ${ }_{2} \mathrm{R}$ mutants using the X-treme-Gene HP (Roche) agent. At $48 \mathrm{~h}$ post transfection, the media was removed and the cells were washed with fresh Hank's Balanced Salt Solution. Cells were either stimulated directly with a range of $\mathrm{LTD}_{4}$ concentrations $\left(10^{-12}-10^{-6} \mathrm{M}\right)$ prepared in $\mathrm{IP}_{1}$ stimulation buffer, or sequentially stimulated with a range of antagonist concentrations $\left(10^{-11}-10^{-5} \mathrm{M}\right)$, and $\mathrm{LTD}_{4}$ concentrations corresponding to the $\mathrm{EC}_{80}$ for each mutant. No $\mathrm{LTD}_{4}$ degradation was observed by mass spectrometry (Supplementary Fig. 8). After equilibration for $30 \mathrm{~min}$ at $37^{\circ} \mathrm{C}$, the cells were lysed with $\mathrm{IP}_{1}-\mathrm{D} 2$ and $\mathrm{Ab}$-Crypt reagents in lysis buffer and then incubated for $1 \mathrm{~h}$ at RT. Fluorescence signal was recorded on a Tecan GENios Pro plate reader using an HTRF filter set $\left(\lambda_{\mathrm{ex}} 320 \mathrm{~nm}, \lambda_{\mathrm{em}}\right.$ 620 and $655 \mathrm{~nm}$ ). Data were plotted using the three parameters $\mathrm{EC}_{50} / \mathrm{IC}_{50}$ fit in GraphPad Prism 7 (San Diego, CA) and represent the mean \pm s.d. of at least two independent experiments performed in quadruplicate.

Quantification of $\mathbf{L T D}_{\mathbf{4}}$ degradation in $\mathbf{I P}_{\mathbf{1}}$ assay. Potential conversion of $\mathrm{LTD}_{4}$ into $\mathrm{LTC}_{4}$ or $\mathrm{LTE}_{4}$ was checked by ultra-performance liquid chromatography coupled to mass spectrometry (UPLC/MS). HEK293 cells were seeded in a 6-well plate at a density of 300,000 cells per well. Forty-eight hours after seeding, medium was removed, and cells were washed twice with PBS. Then cells were incubated in stimulation buffer used for IP-One assays (Krebs buffer containing $\mathrm{LiCl}$ as an inhibitor of $\mathrm{IP}_{1}$ degradation) alone or containing $10 \mu \mathrm{M} \mathrm{LTD} \mathrm{LT}_{4}$ or $10 \mu \mathrm{MTD}_{4}$ and $10 \mathrm{mM} \mathrm{L}^{-C y s t e i n e ~(u s e d ~ a s ~ a n ~ i n h i b i t o r ~ o f ~} \mathrm{LTD}_{4}$ conversion) for $30 \mathrm{~min}$ at $37^{\circ} \mathrm{C}$. After incubation, supernatant was filtered through a $0.22 \mu \mathrm{m}$ PVDF filter and an internal standard was added before injection on UPLC/MS (Waters UPLC system coupled with a SQ detector 2 and a PDA e $\lambda$ detector, using an Acquity UPLC BEH C18 column, $2.1 \mathrm{~mm} \times 50 \mathrm{~mm}, 1.7 \mu \mathrm{m}$ spherical size). UPLC chromatograms were recorded using the following gradient: water $+0.1 \%$ TFA and acetonitrile $(0 \rightarrow 0.2 \mathrm{~min}, 5 \%$ acetonitrile; $0.2 \rightarrow 1.5 \mathrm{~min}$ $5 \% \rightarrow 95 \% ; 1.5 \rightarrow 1.8 \mathrm{~min}, 95 \% ; 1.8 \rightarrow 2.0 \mathrm{~min}, 95 \% \rightarrow 5 \%$; and $2.0 \rightarrow 2.5 \mathrm{~min}$, $5 \%)$. Quantification was done by determining the area under the curve (AUC) ratio of the tested compound over AUC of the internal standard. $0 \%$ was determined by using results from stimulation buffer alone and $100 \%$ was determined by using results from stimulation buffer containing $\mathrm{LTD}_{4}$ but without incubation over the cell monolayer. Quantification results are expressed as mean \pm s.e.m. of three independent experiments.

Cell surface expression determined by ELISA. HEK293 cells were seeded in 24 well plates coated with poly-L-Lysine (Sigma) at 100,000 cells per well and transfected with $375 \mathrm{ng}$ of plasmid coding for the wild-type or mutant $\mathrm{CysLT}_{2} \mathrm{R}$ using X-treme-Gene HP (Roche). Forty-eight hours after transfection, cells were fixed with $3.7 \%(\mathrm{v} / \mathrm{v})$ formaldehyde in Tris-buffered saline (TBS, $20 \mathrm{mM}$ Tris- $\mathrm{HCl}$, $\mathrm{pH} 7.5$, and $150 \mathrm{mM} \mathrm{NaCl}$ ) for $5 \mathrm{~min}$ at RT. Cells were washed three times with TBS and incubated for $1 \mathrm{~h}$ in TBS supplemented with $3 \%(\mathrm{w} / \mathrm{v})$ fat-free 
milk in order to block nonspecific binding sites. A mouse monoclonal anti-HA antibody coupled to HRP (Roche) was added at 1:1000 dilution in TBS-3\% fat-free dry milk for $3 \mathrm{~h}$ at RT. Following incubation, cells were washed twice with TBS before the addition of $250 \mu \mathrm{l}$ of 3,3',5,5'-Tetramethylbenzidine (Sigma). Plates were incubated for $15 \mathrm{~min}$ at RT and the reaction was stopped by the addition of $250 \mu \mathrm{l}$ of $2 \mathrm{~N} \mathrm{HCl}$. Two hundred microliters of the yellow reaction was transferred into a 96-well plate and the absorbance was read at $450 \mathrm{~nm}$ on GENios Pro plate reader (Tecan). Cells transfected with the empty pcDNA3.1+ vector (mock) were used to determine background. Data were plotted using GraphPad Prism 7 and represent the mean \pm s.d. of at least two independent experiments performed in quadruplicate.

Molecular docking. We collected $18 \mathrm{O}$ - and N-derivatives of the common 3,4dihydro-2H-1,4-benzoxazine-2-carboxylic acid scaffold from previous studies $^{30,32}$, assigned charges for the ligands at $\mathrm{pH} 7.0$, and generated 3D ligand structures from their 2D representations, using Monte Carlo optimization and the MMFF-94 force field. We preprocessed each protein structure $\left(\mathrm{CysLT}_{1} \mathrm{R}-\right.$ pranlukast, PDB ID 6RZ4; CysLT $_{2}$ R-11a, PDB ID 6RZ6) by adding missing residues, optimizing side-chain rotamers, and removing water molecules. Rectangular boxes enclosing ligand-binding sites of pranlukast in $\mathrm{CysLT}_{1} \mathrm{R}$ and cpd $11 \mathrm{a}$ in $\mathrm{CysLT}_{2} \mathrm{R}$ with an additional $8 \AA$ margin were used as the sampling space for docking. Receptors were presented as smoothened grid potentials, while the docking simulations sampled ligand conformations in the internal coordinate space using biased probability Monte Carlo optimization ${ }^{57}$ with the sampling parameter (docking effort) set to 50 . We performed at least two independent docking runs for each ligand and selected binding poses with the lowest docking score. All docking simulations were done using the ICM-Pro v3.8-6 software package (MolSoft).

MD simulations. The initial Cys $\mathrm{LT}_{2} \mathrm{R}$ models for $\mathrm{MD}$ simulations were prepared based on the crystal structures (CysLT 2 R-11a, PDB ID 6RZ6, for the inactive state; CysLT 2 R-11c, PDB ID 6RZ8 for the intermediate state) using the ICM-Pro molecular modeling package (v3.8-6). First, BRIL-fusions and all hetero atoms were removed, followed by the assignments of protonation states and modeling missing side-chain residues using internal coordinate mechanics force field. Then missing loops were modeled using the loop modeling and regularization protocols available in ICM-Pro ${ }^{58}$. These preprocessed CysLT $\mathrm{T}_{2} \mathrm{R}$ models were used to prepare input files for $\mathrm{MD}$ simulations as previously described ${ }^{59}$. Briefly, the input files were generated using the CHARMM-GUI server ${ }^{60}$. The receptor orientation was calculated by superimposing the CysLT ${ }_{2} \mathrm{R}$ structures on the CB1 receptor coordinates (PDB ID 5XRA) obtained from the OPM database ${ }^{61}$. The input simulation box had 157 POPC lipids, 11,908 water molecules, and 31 sodium and 46 chloride ions. The system was first energy minimized and then equilibrated for $10 \mathrm{~ns}$, followed by ten independent production runs of $500 \mathrm{~ns}$ each using Gromacs (v.2018.1) simulation package ${ }^{62}$. The analysis and plotting were performed using Gromacs and matplotlib plotting packages available in Python. The MD simulations were performed on GPU enabled nodes with P100 NVIDIA cards made available by the High-Performance Computing Center at the University of Southern California.

Ligand synthesis and characterization. The overall ligand synthesis scheme is shown in Supplementary Fig. 1 and described in Supplementary Methods. Analytical samples were homogeneous as confirmed by TLC, and afforded spectroscopic results consistent with the assigned structures. Proton and carbon nuclear magnetic resonance spectra $\left({ }^{1} \mathrm{H}\right.$ and ${ }^{13} \mathrm{C}$ NMR) were taken on a Varian Mercury 300 spectrometer using deuterated chloroform $\left(\mathrm{CDCl}_{3}\right)$ and deuterated dimethylsulfoxide (DMSO- $d_{6}$ ) as the solvent. Fast atom bombardment mass spectra were obtained on a JEOL JMS-DX303HF spectrometer. Electrospray ionization (HRMS) mass spectra was obtained on a Thermo Fisher Scientific LTQ Orbitrap XL system. Column chromatography was carried out on silica gel (Merck Silica Gel 60, Wako gel C-200, or Fuji Silysia FL60D). Thin layer chromatography was performed on silica gel (Merck TLC or HPTLC plates, Silica Gel 60 F254).

Reporting summary. Further information on research design is available in the Nature Research Reporting Summary linked to this article.

\section{Data availability}

Data supporting the findings of this manuscript are available from the corresponding authors upon reasonable request. A reporting summary for this article is available as a Supplementary Information file. The source data underlying Supplementary Figs. 5 and 6 are provided as a Source Data file. Coordinates and structure factors have been deposited in the Protein Data Bank (PDB) under the accession codes 6RZ6 (CysLT 2 R-11a, C222 space group), 6RZ7 (CysLT 2 R-11a, F222 space group), 6RZ8 (CysLT $\left.{ }_{2} \mathrm{R}-11 \mathrm{c}\right)$, and 6RZ9 (CysLT 2 R-11b)

Received: 27 August 2019; Accepted: 1 November 2019; Published online: 06 December 2019

\section{References}

1. Back, M. et al. International Union of Basic and Clinical Pharmacology. LXXXIV: leukotriene receptor nomenclature, distribution, and pathophysiological functions. Pharmacol. Rev. 63, 539-584 (2011).

2. Lynch, K. R. et al. Characterization of the human cysteinyl leukotriene CysLT1 receptor. Nature 399, 789-793 (1999).

3. Heise, C. E. et al. Characterization of the human cysteinyl leukotriene 2 receptor. J. Biol. Chem. 275, 30531-30536 (2000).

4. Singh, R. K., Tandon, R., Dastidar, S. G. \& Ray, A. A review on leukotrienes and their receptors with reference to asthma. J. Asthma 50, 922-931 (2013).

5. Yokomizo, T., Nakamura, M. \& Shimizu, T. Leukotriene receptors as potential therapeutic targets. J. Clin. Investig. 128, 2691-2701 (2018).

6. Tsai, M.-J. et al. Cysteinyl leukotriene receptor antagonists decrease cancer risk in asthma patients. Sci. Rep. 6, 23979 (2016).

7. Colazzo, F., Gelosa, P., Tremoli, E., Sironi, L. \& Castiglioni, L. Role of the cysteinyl leukotrienes in the pathogenesis and progression of cardiovascular diseases. Mediators Inflamm. 2017, 2432958 (2017).

8. Miligkos, M. et al. Leukotriene receptor antagonists versus placebo in the treatment of asthma in adults and adolescents: a systematic review and metaanalysis. Ann. Intern. Med. 164, 756-767 (2015).

9. Takasaki, J. et al. The molecular characterization and tissue distribution of the human cysteinyl leukotriene CysLT(2) receptor. Biochem. Biophys. Res. Commun. 274, 316-322 (2000).

10. Jiang, Y., Borrelli, L. A., Kanaoka, Y., Bacskai, B. J. \& Boyce, J. A. CysLT2 receptors interact with CysLT1 receptors and down-modulate cysteinyl leukotriene dependent mitogenic responses of mast cells. Blood 110, 3263-3270 (2007).

11. Capra, V. Molecular and functional aspects of human cysteinyl leukotriene receptors. Pharmacol. Res. 50, 1-11 (2004).

12. Fukai, $\mathrm{H}$. et al. Association between a polymorphism in cysteinyl leukotriene receptor 2 on chromosome 13q14 and atopic asthma. Pharmacogenetics 14, 683-690 (2004).

13. Pillai, S. G. et al. A coding polymorphism in the CYSLT2 receptor with reduced affinity to LTD4 is associated with asthma. Pharmacogenetics 14, 627-633 (2004).

14. Yonetomi, Y. et al. Effects of ONO-6950, a novel dual cysteinyl leukotriene 1 and 2 receptors antagonist, in a guinea pig model of asthma. Eur. J. Pharmacol. 765, 242-248 (2015).

15. Shi, Q. J. et al. Intracerebroventricular injection of HAMI 3379, a selective cysteinyl leukotriene receptor 2 antagonist, protects against acute brain injury after focal cerebral ischemia in rats. Brain Res. 1484, 57-67 (2012).

16. Luginina, A. et al. Structure-based mechanism of cysteinyl leukotriene receptor inhibition by antiasthmatic drugs. Sci. Adv. 5, eaax2518 (2019).

17. Chun, E. et al. Fusion partner toolchest for the stabilization and crystallization of G protein-coupled receptors. Structure 20, 967-976 (2012).

18. Stauch, B. et al. Structural basis of ligand recognition at the human MT1 melatonin receptor. Nature 569, 284-288 (2019).

19. Ballesteros, J. A. \& Weinstein, H. Integrated methods for the construction of three-dimensional models and computational probing of structure-function relations in G protein-coupled receptors. Methods Neurosci. 25, 366-428 (1995).

20. Caffrey, M. \& Cherezov, V. Crystallizing membrane proteins using lipidic mesophases. Nat. Protoc. 4, 706-731 (2009).

21. Wheatley, M. et al. Lifting the lid on GPCRs: the role of extracellular loops. Br. J. Pharmacol. 165, 1688-1703 (2012).

22. Katritch, V. et al. Allosteric sodium in class A GPCR signaling. Trends Biochem. Sci. 39, 233-244 (2015).

23. Popov, P. et al. Computational design of thermostabilizing point mutations for G protein-coupled receptors. Elife 7, e34729 (2018)

24. Zarzycka, B., Zaidi, S. A., Roth, B. L. \& Katritch, V. Harnessing Ion-binding sites for GPCR pharmacology. Pharmacol. Rev. 71, 571-595 (2019).

25. White, K. L. et al. Structural connection between activation microswitch and allosteric sodium site in GPCR signaling. Structure 26, 259-269 (2018).

26. Venkatakrishnan, A. J. et al. Molecular signatures of G-protein-coupled receptors. Nature 494, 185-194 (2013).

27. Delos Santos, N. M., Gardner, L. A., White, S. W. \& Bahouth, S. W. Characterization of the residues in helix 8 of the human $\beta 1$-adrenergic receptor that are involved in coupling the receptor to G proteins. J. Biol. Chem. 281, 12896-12907 (2006).

28. Kirchberg, K. et al. Conformational dynamics of helix 8 in the GPCR rhodopsin controls arrestin activation in the desensitization process. Proc. Natl. Acad. Sci. USA 108, 18690-18695 (2011).

29. Roth, C. B., Hanson, M. A. \& Stevens, R. C. Stabilization of the human $\beta 2-$ adrenergic receptor TM4-TM3-TM5 helix interface by mutagenesis of Glu1223.41, a critical residue in GPCR structure. J. Mol. Biol. 376, 1305-1319 (2008)

30. Itadani, S. et al. Discovery of highly potent dual CysLT1 and CysLT2 antagonist. ACS Med. Chem. Lett. 5, 1230-1234 (2014). 
31. Itadani, S. et al. Discovery of a potent, orally available dual CysLT1 and CysLT2 antagonist with dicarboxylic acid. Bioorg. Med. Chem. 23, 2079-2097 (2015).

32. Itadani, S. et al. Discovery of gemilukast (ONO-6950), a dual CysLT 1 and CysLT 2 antagonist as a therapeutic agent for asthma. J. Med. Chem. 58, 6093-6113 (2015).

33. Thompson, M. D. et al. A cysteinyl leukotriene 2 receptor variant is associated with atopy in the population of Tristan da Cunha. Pharmacogenetics 13, 641-649 (2003).

34. Ceraudo, E. et al. Uveal melanoma oncogene CYSLTR2 encodes a constitutively active GPCR highly biased toward Gq signaling. Preprint at https://www.biorxiv.org/content/10.1101/663153v1 (2019).

35. Moore, A. R. et al. Recurrent activating mutations of G-protein-coupled receptor CYSLTR2 in uveal melanoma. Nat. Genet. 48, 675-680 (2016).

36. Moller, I. et al. Activating cysteinyl leukotriene receptor 2 (CYSLTR2) mutations in blue nevi. Mod. Pathol. 30, 350-356 (2017).

37. Yuan, S., Filipek, S., Palczewski, K. \& Vogel, H. Activation of G-proteincoupled receptors correlates with the formation of a continuous internal water pathway. Nat. Commun. 5, 4733 (2014).

38. Vickery, O. N. et al. Intracellular transfer of $\mathrm{Na}+$ in an active-state G-proteincoupled receptor. Structure 26, 171-180.e2 (2018).

39. Tao, Y. X. Constitutive activation of G protein-coupled receptors and diseases: insights into mechanisms of activation and therapeutics. Pharmacol. Ther. 120, 129-148 (2008)

40. Lek, M. et al. Analysis of protein-coding genetic variation in 60,706 humans. Nature 536, 285-291 (2016).

41. Hauser, A. S. et al. Pharmacogenomics of GPCR drug targets. Cell 172, 41-54 (2018).

42. Bäck, M. et al. Update on leukotriene, lipoxin and oxoeicosanoid receptors: IUPHAR review 7. Br. J. Pharmacol. 171, 3551-3574 (2014).

43. Matsuda, M. et al. Increased expression of CysLT2 receptors in the lung of asthmatic mice and role in allergic responses. Prostaglandins Leukot. Essent. Fat. Acids 131, 24-31 (2018).

44. Yonetomi, Y. et al. Leukotriene C4 induces bronchoconstriction and airway vascular hyperpermeability via the cysteinyl leukotriene receptor 2 in S-hexyl glutathione-treated guinea pigs. Eur. J. Pharmacol. 754, 98-104 (2015).

45. Ghosh, A., Chen, F., Thakur, A. \& Hong, H. Cysteinyl leukotrienes and their receptors: emerging therapeutic targets in central nervous system disorders. CNS Neurosci. Ther. 22, 943-951 (2016).

46. Magnusson, C. et al. Low expression of CysLT1R and high expression of CysLT2R mediate good prognosis in colorectal cancer. Eur. J. Cancer 46, 826-835 (2010).

47. Thompson, M. D. et al. A functional G300S variant of the cysteinyl leukotriene 1 receptor is associated with atopy in a Tristan da Cunha isolate. Pharmacogenet. Genomics 17, 539-549 (2007).

48. Li, X. et al. Crystal structure of the human cannabinoid receptor CB2. Cell 176, 459-467 (2019).

49. Tan, Q. et al. Structure of the CCR5 chemokine receptor-HIV entry inhibitor maraviroc complex. Science 341, 1387-1390 (2013).

50. Murray, J. W. et al. Parameters affecting the X-ray dose absorbed by macromolecular crystals. J. Synchrotron Radiat. 12, 268-275 (2005).

51. Bourenkov, G. P. \& Popov, A. N. A quantitative approach to data-collection strategies. Acta Crystallogr. Sect. D. Biol. Crystallogr. 62, 58-64 (2006).

52. Zander, U. et al. MeshAndCollect: an automated multi-crystal data-collection workflow for synchrotron macromolecular crystallography beamlines. Acta Crystallogr. Sect. D. Biol. Crystallogr. 71, 2328-2343 (2015).

53. Kabsch, W. XDS. Acta Crystallogr. Sect. D. Biol. Crystallogr. 66, 125-132 (2010).

54. McCoy, A. J. et al. Phaser crystallographic software. J. Appl. Crystallogr. 40, 658-674 (2007).

55. Bricogne, G. et al. BUSTER version 2.10.3. (United Kingdom Glob. Phasing Ltd, Cambridge, 2011).

56. Adams, P. D. et al. PHENIX: a comprehensive Python-based system for macromolecular structure solution. Acta Crystallogr. Sect. D. Biol. Crystallogr. 66, 213-221 (2010).

57. Totrov, M., Abagyan, R. \& Raffa, R. B. Protein-ligand docking as an energy optimization problem. in Drug-receptor thermodynamics: introduction and experimental applications (ed. Raffa, R. B.) 603-624 (John Wiley \& Sons, 2001).

58. Abagyan, R., Totrov, M. \& Kuznetsov, D. ICM - a new method for protein modeling and design: applications to docking and structure prediction from the distorted native conformation. J. Comput. Chem. 15, 488-506 (1994).

59. Zhang, H. et al. Structural basis for selectivity and diversity in angiotensin II receptors. Nature 544, 327-332 (2017).

60. Jo, S., Kim, T., Iyer, V. G. \& Im, W. CHARMM-GUI: a web-based graphical user interface for CHARMM. J. Comput. Chem. 29, 1859-1865 (2008).

61. Lomize, M. A., Pogozheva, I. D., Joo, H., Mosberg, H. I. \& Lomize, A. L. OPM database and PPM web server: resources for positioning of proteins in membranes. Nucleic Acids Res. 40, D370-376 (2012).
62. Abraham, M. J. et al. Gromacs: high performance molecular simulations through multi-level parallelism from laptops to supercomputers. SoftwareX 1-2, 19-25 (2015).

\section{Acknowledgements}

We thank S. Ustinova, A. Awawdeh, P. Utrobin, J. Velasquez, and Yu. Kovalev for technical assistance, C. Hanson, K. Villers, and M. Chu for their help with insect and mammalian cells expression, the Structural Biology Group of the ESRF, and especially A.N. Popov for assistance with data collection. We also thank the High-Performance Computing Center at the University of Southern California for providing computing resources. This work was supported in part by the Russian Science Foundation projects 19-14-00261 (A.G., A.L., E.M., A.M., and M.S.) and 18-74-00117 (P.P.) and the GPCR consortium (V.C.). V.B. acknowledges support from the Ministry of Science and Higher Education of the Russian Federation (project 6.9909.2017/6.7). V.G. acknowledges the special agreement CEA (IBS)-HGF(FZJ) STC 5.1, the Grenoble Instruct Centre (ISBG; UMS 3518 CNRS-CEA-UJFEMBL), the French Infrastructure for Integrated Structural Biology (FRISBI; ANR-10-INSB05-02), and the New Generation of Drugs for Alzheimer's Disease project (GRAL; ANR-10LABX-49-01) within the Grenoble Partnership for Structural Biology. B.S. was supported by a fellowship from EMBO (ALTF 677-2014). É.B.O. was supported by a research fellowship from the Institut de Pharmacologie de Sherbrooke and Centre d'excellence en neurosciences de l'Université de Sherbrooke. R.B. was supported by a research fellowship from the Canadian Institutes of Health Research and from the Fonds de Recherche en Santé du Québec. P.S. holds a Canada Research Chair in Neurophysiopharmacology of Chronic Pain.

\section{Author contributions}

A.G. and A.L. optimized the constructs, developed the expression and purification procedure, expressed and purified the proteins, screened the ligands, crystallized the protein-ligand complexes, collected synchrotron data, and prepared initial draft. A.G., A.L., E.M., V.B., K.K. and A.M. collected X-ray diffraction data at synchrotron. É.B.O., R.B., J.M.L. and P.S. performed and analyzed cell signaling and cell surface assays. T.F. and T.M. provided ligands, and performed SAR analysis. E.M. and V.B. processed diffraction data. E.M., V.B. and G.W.H. performed structure determination and refinement. V.B., V.C., A.G., A.L., P.P., E.M., A.M., G.W.H. and V.K. performed project data analysis/interpretation. B.S. provided advice on construct design. A.I., A.S., and M.S. helped with construct optimization, protein expression and purification. D.R., P.P. and V.K. prepared structural models for docking, performed molecular docking, structure-activityrelationship, and structure analysis. N.P. and V.K. performed MD simulations and data analysis. A.G., A.L., V.C., P.P., V.B. and V.K. wrote the manuscript with help from other authors. V.C, V.G., A.M. and V.B. initiated the project. A.M. and V.B. organized the project implementation, were responsible for the overall project management, and cosupervised the research. V.C. supervised the overall project.

\section{Competing interests}

T.F. and T.M. are employees of Ono Pharmaceutical. Other authors declare no com peting interests.

\section{Additional information}

Supplementary information is available for this paper at https://doi.org/10.1038/s41467 019-13348-2.

Correspondence and requests for materials should be addressed to P.S., A.M. or V.C.

Peer review information Nature Communications thanks the anonymous reviewers for their contribution to the peer review of this work. Peer reviewer reports are available.

Reprints and permission information is available at http://www.nature.com/reprints

Publisher's note Springer Nature remains neutral with regard to jurisdictional claims in published maps and institutional affiliations.

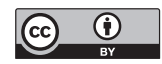

Open Access This article is licensed under a Creative Commons Attribution 4.0 International License, which permits use, sharing, adaptation, distribution and reproduction in any medium or format, as long as you give appropriate credit to the original author(s) and the source, provide a link to the Creative Commons license, and indicate if changes were made. The images or other third party material in this article are included in the article's Creative Commons license, unless indicated otherwise in a credit line to the material. If material is not included in the article's Creative Commons license and your intended use is not permitted by statutory regulation or exceeds the permitted use, you will need to obtain permission directly from the copyright holder. To view a copy of this license, visit http://creativecommons.org/ licenses/by/4.0/.

(C) The Author(s) 2019 